\title{
Knowledge-Based View:
}

\author{
A New Theory of Strategy? \\ Kathleen M. Eisenhardt \\ kme@leland.stanford.edu \\ Filipe M. Santos \\ fsantos@stanford.edu
}

Dept. of Management Science and Engineering

Stanford University, CA 94305-4026 USA ${ }^{1}$

Forthcoming

In A. Pettigrew, H. Thomas, and R. Whittington (Eds.)

Handbook of Strategy and Management

Sage Publications

Version: July 27, 2000

Characters count (no spaces): 101966 


\section{Introduction}

The knowledge movement is sweeping through the field of strategy. The last severalyears have witnessed the widespread use of a knowledge perspective for research on a variety of topics within strategy, including alliances (e.g. Mowery, Oxley et al., 1996; Simonin, 1999), capabilities transfer (e.g. Zander and Kogut, 1995; Szulanski, 1996), acquisitions (e.g. Ranft and Lord, 1998; Zollo and Singh, 1999) and product development (e.g. Hargadon and Sutton, 1997; Hansen, 1999). An emerging Knowledge-Based View $(\mathrm{KBV})$ of strategy underlies this research. This perspective considers knowledge as the most strategically significant resource of the firm (Grant, 1996), and its proponents argue that heterogeneous knowledge bases and capabilities among firms are the main determinants of sustained competitive advantage and superior corporate performance (Decarolis and Deeds, 1999; Winter and Szulanski, 1999).

What is the impact of this focus on knowledge for the field of strategy? The answer is unclear because agreement on the nature of organizational knowledge, the specifics of the knowledge-based view (KBV), and whether such a view constitutes a theory of strategy, a theory of the firm, or both, has yet to emerge. Additionally, empirical research based on the knowledge perspective is extensive, but there is no consensus understanding on whether that research supports the existing theory (Patriotta and Pettigrew, 1999), or adds predictive power to other theories of strategy.

Some researchers argue that KBV is an outgrowth of resource-based thinking where the concept of resources is extended to include intangible assets and, specifically, knowledge-based resources (Grant, 1996; Decarolis and Deeds, 1999). But then, is KBV really just a re-labeling of resource-based thinking that adds little to our current understanding of the sources of superior performance? Other researchers see KBV as a useful extension of organizational learning to strategy and organization theory, an extension that is capable of informing research and providing new insights into organizational functioning (Kogut and Zander, 1992; Kogut and Zander, 1996). Still others argue that knowledge should be treated as a process of 
ongoing social construction and not as a resource (Spender, 1996). Finally, some believe that a theory must contain a theory of the firm if it is to be a theory of strategy at all (Conner and Prahalad, 1996). Given this variety of perspectives, is the knowledge movement just a fad? Or does it represent the emergence of a new theory of strategy, contributing to our ability to understand the sources of superior firm performance? Or is it more accurately a new theory of organization? The purpose of this chapter is to address these questions.

The chapter is organized into four sections. We begin with a theoretical discussion of KBV that covers varying views on the nature of knowledge, several streams of thinking that underlie $\mathrm{KBV}$, and a variety of theoretical statements about what a knowledge-based theory of strategy might be. We then examine the empirical literature on $\mathrm{KBV}$, within strategy and closely related fields, by focusing on four major streams of research on knowledge: sourcing, internal transfer, external transfer, and integration. We end by addressing the questions that we posed at the beginning of this chapter and offering some directions for future research.

We have several major conclusions. First, KBV offers a number of useful and empirically grounded insights into the multilevel social processes through which knowledge is sourced, transferred, and integrated, within and across organizations. Second, since the empirical research indicates that these knowledge processes are largely similar within and across organizations, $\mathrm{KBV}$ is not as yet a theory of organization. There is, however, some exciting new theoretical work emphasizing organizational identity and 'knowledge as knowing' that may become such a theory. Finally, when KBV is used as a theory of strategy, knowledge is conceptualized as a resource that can be acquired, transferred, or integrated to achieve sustained competitive advantage. In our view, KBV then reduces to simply a special case of resource-based thinking, rather than a unique theory of strategy. Further, it rests on the tenuous assumption that knowledge is the firm's most important resource. Therefore, knowledge-based thinking is enormously important for understanding a number of central topics in strategy, including acquisitions, alliances, and strategic choice, but it is not as yet a unique theory about how firm managers create competitive advantage. It is not as yet a new theory of strategy. 


\section{Origins and Development of the Knowledge-Based View}

Researchers in the strategy field have traditionally used a concept of knowledge that is grounded in Western epistemology ${ }^{2}$. Knowledge is considered as "justified true belief" and the focus of theories is on the explicit nature of knowledge (Nonaka and Takeuchi, 1995). In other words, knowledge is modeled as an unambiguous, reducible and easily transferable construct, while knowing is associated with processing information. This approach to knowledge has given rise to several theories that suggest a machine-like functioning of organizations. For example, scientific management theories posit that the organization of work should be entirely determined by codified knowledge, and that the knowledge of the firm is held by a select number of individuals. Similarly, the information-processing perspective treats organizations as machines that use rules and routines to address the individual information processing requirements caused by interdependent work and environmental uncertainty (Santos, 1999).

In contrast with this traditional conception, a newer view of knowledge, based on the distinction between explicit and tacit knowledge (Polanyi, 1962), has emerged. Tacit knowledge is linked to the individual, and is very difficult, or even impossible, to articulate. Only through observation and doing is it possible to learn this type of knowledge. As knowledge is explored, put into action and socially justified, some part of it may be codified (i.e., made more explicit), by being converted into messages that can then be processed as information and transmitted. Nonetheless, information and explicit knowledge are considered distinct constructs, since there is always a certain degree of interpretive ambiguity due to specific contexts and individual perspectives (Tell, 1997). The process of knowledge codification requires the development of mental models and the existence of a language in which knowledge can be articulated. In addition, since codification entails a transformation in the organization of knowledge, it is always a process of creation (Cowan and Foray, 1997) and does not replace entirely the more tacit knowledge on which it is based. This distinction between tacit and explicit knowledge has proven to be particularly important in the dominant 
knowledge-based approach to strategy (e.g. Kogut and Zander, 1992; Grant, 1996). That approach identifies tacit knowledge as the most strategic resource of firms. The argument is that, since tacit knowledge is difficult to imitate and relatively immobile, it can constitute the basis of sustained competitive advantage (Grant, 1996; Decarolis and Deeds, 1999; Gupta and Govindarajan, 2000).

Yet even as mainstream strategy scholars began emphasizing the implications of tacit vs. explicit knowledge, a more recent epistemology has emerged in the strategy and learning literatures, particularly in Europe (Blackler, 1993; Weick and Roberts, 1993; Blackler, 1995; Spender, 1996; Von_Krogh, Roos et al., 1998; Cook and Brown, 1999; Patriotta and Pettigrew, 1999). The foundations of this approach are deeply rooted in cognitive psychology and sociology. As such, this approach focuses more on the process of knowing than on knowledge as an objective and transferable resource. Knowledge is considered socially constructed and the creation of meaning occurs in ongoing social interactions grounded in working practices (Weick and Roberts, 1993; Cook and Brown, 1999) and the specifics of the social and cultural setting (Blackler, 1995; Galunic and Rodan, 1999). Instead of a cognitive representation of reality, knowledge is a creative activity of constructing reality (Von_Krogh, Roos et al., 1994). Thus, truth should be considered more as a goal of the knowledge creation process than an absolute characteristic of knowledge (Tell, 1997).

Overall, this approach goes beyond the dominant conception of knowledge as a resource that can assume tacit or explicit forms. In this newer epistemology, knowledge is associated with a process phenomenon of knowing that is clearly influenced by the social and cultural settings in which it occurs. With these varying views of knowledge in mind, we turn now to the streams of thinking that underlie KBV.

\section{Organizational Learning as a Foundation for the Knowledge-based View}

Organizational learning is part of the foundation that underlies knowledge-based thinking. Learning can be defined as the process by which new information is incorporated into the behavior of agents, changing their 
patterns of behavior and possibly, but not always, leading to better outcomes. The initial focus of learning theory was on individuals, using the mechanism of stimulus-response (Weick, 1991). More recently, it has been conceptualized at the organizational level as well, where it is viewed as a key process in the adaptation of organizations to the environment (Argote, 1999).

Penrose's seminal work on the growth of the firm (1959) is an important starting point for understanding organizational learning. Penrose describes how learning processes create new knowledge and form the basis of the growth of organizations through the recombination of existing resources. Shortly thereafter, Cyert and March (1963) developed significant thinking around the concept of organizational routines. Organizational routines form the basis of collective learning in organizations. They are seen as executable capabilities for repeated performance that have been learned by an organization in response to selective pressures (Cohen, Burkhart et al., 1996). These routines represent a manifestation of organizational memory in that they encode inferences from history, and guide individual and group behavior in organizations. Organizational learning is thus perceived as an adaptive change process that is influenced by past experience, focused on developing and modifying routines, and supported by organizational memory (Nonaka and Takeuchi, 1995).

Nelson and Winter (1982) were among the first to integrate organizational knowledge and routines with the notion of dynamic competitive environments. In their approach to evolutionary economics, the firm is understood to be a repository of knowledge, which is represented by routines that guide organizational action. The authors see individuals as responding to information complexity and uncertainty through their own skills and routine organizational activity, in line with the behavioral tradition (Simon 1965; Cyert and March 1963).

Cohen and Levinthal (1990) related organizational learning and innovation to the evolving knowledge base of the firm. The authors define absorptive capacity as the ability to recognize the value of external 
information, assimilate it and apply it to commercial ends. According to the authors, absorptive capacity is largely a function of the level of the firms' prior knowledge (which emphasizes the cumulative nature of knowledge) and is history or path dependent (which emphasizes the importance of earlier decisions). Important determinants of absorptive capacity are the internal channels of communication, the distribution of knowledge in the environment and in the firm, and the pattern of R\&D investment decisions. Specifically, in an environment where knowledge development is widely dispersed and learning requires a strong knowledge base, internal $\mathrm{R} \& \mathrm{D}$ efforts will more significantly contribute to absorptive capacity.

Brown and Duguid (1991) proposed a unified view of working, learning and innovation, which links individual and organizational levels of knowledge. The authors start by pointing out that codification of work procedures can be quite different from actual working practices, and sometimes it is even contradictory. They argue that learning theory should be distanced from codified, transferable and objective notions of knowledge, and focus instead on knowledge in context. In their view, meaningful knowledge is deeply related to daily work, and the acquisition of new knowledge (i.e., learning) is socially constructed from working practices. This social construction of knowledge occurs within informal communities-ofpractice, where knowledge is freely shared through collaborative mechanisms such as narration and joint work. The authors also argue that these communities-of-practice are likely to engage in innovative activities because their view of the world is constantly challenged by the demands of daily work. The informal character of these communities and their fluid membership facilitates innovation and mitigates the ossifying tendencies of large organizations. The dysfunction of this ossification has been clearly demonstrated by Leonard-Barton (1992). She found that, when the level of congruence between capabilities and an innovation project is low, the core capabilities of a firm could become core rigidities and hinder innovation. An organization composed of communities with a certain degree of autonomy and legitimacy to enact new experiments might be able to overcome these rigidities and engage in innovation (Brown and Duguid, 1991). 
This perspective on organizational learning and innovation implies a view of organizations as multiple communities-of-practice. Each community-of-practice is engaging in experimental and interpretative activities with the environment from which sensemaking emerges, leading to adaptive behavior.

Organizations thus evolve based on the competing perspectives of different communities-of-practice (Martin and Carlile, 1999). A number of authors (Lave and Wenger, 1991; Blackler, 1995; Whitaker, 1996; Nahapiet and Goshal, 1998; Galunic and Rodan, 1998) have extended this emphasis on communities-ofpractice, recognizing knowledge as contextual and situated in a broader range of settings.

\section{Dynamic Capabilities as a Foundation for the Knowledge-Based View}

The dynamic capabilities approach is a second foundation that underlies knowledge-based thinking. In the traditional economic vision of the firm, managers' decisions are based on a set of productive and environmental conditions. Since this is an equilibrium-based perspective, theory does not need to explain how knowledge in organizations is created or how it changes over time (Nonaka and Takeuchi, 1995). Managers need not change their firms routinely because the basic characteristics that define the environment and the structure of competition are stable, or at least predictable. Given these assumptions, a strategic theory that addresses the cross-sectional problem of explaining superior performance at a given point in time is helpful in addressing the more important longitudinal problem of explaining how firms achieve superior performance over time (Porter, 1991). In other words, competitive advantage is sustainable in static or slow-moving environments.

Until the past decade, this equilibrium-based thinking dominated the major paradigms of strategy. For example, according to the industrial organization approach, sustainable competitive advantage can be achieved by developing and defending profitable positions in attractive industries (Porter, 1985). According to the resource-based view, valuable, rare, inimitable and non-substitutable (VRIN) resources (Wernerfelt, 1984; Barney, 1991), and related sets of operational routines and technological skills (Pralahad and Hamel, 
1990; Stalk, Evans et al., 1992) are sources of sustainable advantage for firms. Even strategy conflict approaches, that use game-theory concepts to explore the dynamics of competition, argue that superior performance can be sustained by competing through a clever sequence of strategic moves and countermoves in a well-defined strategic game (Shapiro, 1989). This last approach can thus be described as 'exploring the dynamics of a largely static world' (Porter, 1991: 106).

The increasing dynamism of the environment, with its frequent and rapid changes in technology, customer preferences, and competition, has led a number of researchers ( e.g., Eisenhardt, 1989; D'Aveni, 1994) to question the sustainability of superior performance of any given strategic position, bundle of resources or set of moves. This means that understanding superior performance at a point in time explains very little of how superior performance is consistently achieved over time (Grant, 1996) or indeed, if it can be achieved at all (D'Aveni, 1994; Eisenhardt and Martin, 2000). In high-velocity environments, an extreme form of dynamic markets where even basic industry characteristics such as boundaries, competitors and customers are in flux, no specific advantages are sustainable. Rather, superior performance occurs by continuously creating temporary advantages. In these situations, the ability to learn quickly in order to alter the resource configuration in adaptation to market change becomes crucial to performance.

Given these observations, strategy theorists began a quest for a dynamic theory of strategy, a theory that could reveal the sources of superior performance in dynamic environments (Porter, 1991; Spender, 1996; Teece, Pisano et al., 1997; Brown and Eisenhardt, 1998). This quest was approached both by developing new strategic paradigms like complexity approaches to strategy (Brown and Eisenhardt, 1998), as well as by extending existing ones, like the dynamic capabilities extension to the resource-based view (Teece, Pisano et al., 1997). The dynamic capabilities approach argues that competitive advantage is dependent on particular organizational and managerial processes, termed 'dynamic capabilities', that are defined as the firm's ability to integrate, build and reconfigure internal and external competencies to address rapidly changing environments (Teece, Pisano et al., 1997). The main challenges for strategy researchers have been 
to define the construct of dynamic capabilities, test their contribution to performance, and understand the evolution of capabilities over time (Eisenhardt and Martin, 2000).

\section{Knowledge-based View of Strategy}

A number of researchers have attempted to integrate the above insights into a theory of strategy and, in some cases, a theory of the firm based on a knowledge perspective. One of the earliest attempts was by Dierickx and Cool (1989). They conceptualized the knowledge of firms in terms of stocks and flows. Stocks of knowledge are accumulated knowledge assets, while flows are knowledge streams within and across organizations that contribute to the accumulation of knowledge. Superiors stocks and flows are seen as sources of sustained competitive advantage and superior performance.

Kogut and Zander (1992) also emphasized the strategic importance of knowledge as a source of advantage and established the foundation for a theory of the firm. They posited that what firms do better than markets is the creation and transfer of knowledge within the organization. In their view, knowledge is held by individuals (know-what and know-how), and yet it is also embedded in the organizing principles by which people voluntarily cooperate in an organizational context. Because the creation of new knowledge depends on existing capabilities and organizing principles, the knowledge of the firm evolves in a path-dependent way, through the replication and recombination of existing knowledge. In what could form the basis for a theory of strategy, the authors also argue that the ability to replicate knowledge determines the firm's rate of growth, but that such replication also facilitates imitation by competitors. Therefore, firms are able to grow and deter competitive imitation only by continuously recombining their knowledge and applying it to new market opportunities. That is, in a competitive environment, superior performance can only be sustained through continuous innovation. 
Nonaka and Takeuchi (1995) complement the work of Kogut and Zander by providing a framework for understanding the integration of individual and organizational knowledge. Consistent with their observations of Japanese companies, the authors argue that organizational knowledge should be understood as the processes that amplify the knowledge created by individuals and crystallize it as a part of the knowledge network of the organization. These processes constitute a knowledge spiral, which is highly iterative and occurs mainly through informal networks of relations in the organization. This spiral involves continuous interplay between tacit and explicit knowledge at individual and organizational levels. The proposed model identifies some enabling conditions for the knowledge creating process, namely the existence of redundancy, requisite variety and a creative chaos.

Grant further articulated the theoretical foundations for a knowledge-based view, both as a theory of organization (1996) and as a theory of strategy (1996a), in what has be come probably the most widely used perspective on knowledge within the strategy field. In this view, tacit knowledge is the source of sustained competitive advantage. However, since production activities usually require the combination of a wide array of specialized knowledge that resides in individuals, organizational capabilities are essential to the achievement of that advantage. In particular, the essence of organizations is their ability to integrate individual specialized knowledge and apply it to new products and services. These capabilities are structured hierarchically according to the scope of knowledge that they integrate. The key integration mechanisms are direction and routines, and the central organizational problem is one of coordination (Grant, 1996).

Based on this understanding of organizations, Grant (1996a) proposed a knowledge-based theory of strategy. He argues that the source of competitive advantage in dynamic environments is not knowledge that is proprietary to the organization, because the value of such knowledge erodes quickly due to obsolescence and imitation. Rather, sustained competitive advantage is determined by non-proprietary knowledge in the form of tacit individual knowledge. Tacit knowledge can form the basis of competitive advantage because it 
is both unique and relatively immobile. Yet, because that knowledge is possessed by individuals and not the organization, a critical element of sustained competitive advantage is the ability to integrate the specialized and tacit knowledge of individuals. Grant identifies three characteristics of knowledge integration that increase its strategic value. The first is the efficiency of integration, which is a function of common knowledge, frequency and variability of tasks, and a structure that economizes on communication. The second is the scope of that integration, with a broader scope facilitating the creation and preservation of competitive advantage. The third is the flexibility of integration to include new knowledge and the reconfiguration of existing knowledge.

In addition, Grant makes the point, also emphasized by other scholars (Kogut and Zander, 1996; Kogut, 2000), that knowledge can also be integrated externally through relational networks that span organizational boundaries. These networks provide efficient mechanisms for accessing and integrating new knowledge, especially in high-velocity environments, where the speed and scope of knowledge integration are paramount for sustaining competitive advantage. Overall, Grant's approach extends the dynamic capabilities view of strategy (Teece, Pisano et al., 1997) and can be considered an outgrowth of resourcebased thinking.

\section{Challenges to the Dominant Knowledge-based View of Strategy}

Although the approach of "knowledge as resource" has become the dominant perspective of KBV in strategy (e.g., Grant, 1996a), it is not without challenge. For example, Spender (1996) argues that a dynamic theory of the firm based on knowledge should be conceptually different from a resource-based approach. Knowledge is not an observable and transferable commodity. Organizations are not collections of rational agents. Rather, Spender argues that organizations learn and have knowledge to the extent that their members are malleable beings whose sense of sef is influenced by the organization's evolving identity, a theme argued by Kogut and Zander (1996) as well. Collective knowledge thus becomes the basis of human 
meaning and communication. The firm is seen as a system of knowing activity, rather than as a system of applied knowledge bundles that can be shuffled about the organization. Specifically, the firm is seen as an evolving, quasi-autonomous system of knowledge production and application, with emergent and selforganizing properties that derive from the interactions of its semi-autonomous elements with one another and the external environment (Spender, 1996).

Spender's approach to KBV is very similar to Brown and Duguid's view of organizations as systems of communities-of-practice (Brown and Duguid, 1991). Further, both these perspectives have much in common with conceptualizing organizations are complex adaptive systems, in which innovative behavior emerges from loosely connected structures among modular actors (Anderson, 1999; Eisenhardt and Bhatia, 2000). This approach to organizations has several normative implications. For the system to be active, managers should preserve and enhance the interpretive flexibility, manage the boundaries of the firm, and identify the institutional influences in the environment (Spender, 1996). In addition, it is important to distinguish between the systemic and component parts of the system. For example (and in contrast to Grant's approach), a core competence is not a collection of knowledge components, but a systemic property emerging from the organization's ongoing activity. Finally, Spender argues that identification of the internal knowledge processes and their organizational meaning is essential for an effective management of organizations. Kogut and Zander (1996) echo similar themes in their discussion of social identity as a basis for a knowledge-based theory of the firm.

Dissatisfaction with the dominant perspective on KBV as a theory of strategy is also clear in the work of other researchers. Similar to Spender (1996), some scholars (Cook and Brown, 1999; Patriotta and Pettigrew, 1999) suggest that the treatment of knowledge that is inherent in the 'knowledge as resource' view is clearly incomplete. These and other authors (e.g., Blackler, 1995; Kogut and Zander, 1996) argue for a more contextual, processual, and situated view of knowledge, with closer ties with learning theory and social identity. Others attack KBV from the perspective of transaction-cost economics, arguing that the 
knowledge-based view of the firm can be subsumed by this earlier perspective (Foss, 1996). Still others question the strategic logic of KBV. Can knowledge can be the most important resource without considering either its strategic value (e.g., Lane and Lubatkin, 1998; Eisenhardt and Galunic, 2000; Gupta and Govindarajan, 2000) or whether that value will actually be appropriated by the firm rather than retained by individual knowledge-holders (Chacar and Coff, 2000)? More fundamentally, other authors (Eisenhardt, 1989; D'Aveni, 1994; Esenhardt and Martin, 2000) question whether sustained competitive advantage is even possible in dynamic environments, especially high-velocity ones. As such, they focus on the ability to change, rather than the possession and use of knowledge, as the central driver of a flow of temporary advantages that leads to superior performance in such environments.

\section{Review of Empirical Research}

In the previous section, we discussed KBV from a theoretical perspective. In this section, we switch our focus to the empirical research on KBV in strategy and related fields. Our thinking is that theoretical discourse goes hand-in-hand with empirical exploration and theory testing.

We have organized this review according to specific knowledge processes: sourcing, internal transfer, external transfer, and integration. Although many categorizations are possible, we chose this one because it is closely linked with the dominant theoretical conception of "knowledge as resource" and with the dominant conception of KBV as theory of strategy in which these knowledge processes are the source of sustained competitive advantage and superior performance (e.g., Grant, 1996a). As such, this categorization reveals significant insights into the empirical validity of current theory, the shape of a potentially more valid theory, and an agenda for future research. In each of the following sub-sections we describe the specific knowledge process, relevant empirical literature and main findings, and draw implications for KBV as both a theory of strategy and a theory of organization. 


\section{Knowledge Sourcing}

To keep pace with dynamic environments, managers frequently need to adapt their firm's knowledge base (Grant, 1996). Given the dispersion of knowledge (both within and outside the firm) and the uncertainty in the environment, knowledge sourcing is an important knowledge process by which managers identify and gain access to relevant knowledge that is being created in the environment. Recent empirical literature reveals some of the mechanisms for effective knowledge sourcing.

In a pharmaceutical industry study, Henderson and Cockburn (1994) used knowledge sourcing arguments to explain research productivity, as measured by patents. The authors collected both qualitative and quantitative data, at the level of research programs, to construct detailed measures of both component and architectural competences. Component competence was associated with specific areas of knowledge such as expertise in hypertension, whereas architectural competence (like dynamic capability) refers to the ability to integrate component competencies in new and flexible ways. The authors found that the allocation of key resources through collaborative rather than dictatorial processes and the existence of pro-publication incentives that promoted links to the wider external scientific community were strongly correlated with research productivity. These variables accounted for 40-50\% increases in productivity. Pro-publication incentives also were strongly correlated with other measures of external knowledge sourcing, namely the proximity of headquarters to a research university and the involvement in collaborative $R \& D$ projects with major research universities.

In more recent work, Henderson and Cockburn (1996) used the same data to test the effect of economies of size and knowledge spillovers in pharmaceutical research productivity, as measured by important patents. They found that research programs located within larger firms are significantly more productive than rival programs located within smaller firms. In particular, research programs in large firms benefited primarily 
from economies of scope in the form of a larger and more diversified knowledge pool, rather than from scale economies due to sharing fixed costs and greater specialization.

These findings are consistent with other studies that link external knowledge sourcing with innovation and performance. For example, Powell et al. (1996) used a knowledge sourcing argument to explain the patterns of alliances in biotechnology firms. Traditional explanations of inter-firm collaborations focus on risk sharing, access to new markets and technologies, speeding products to market and pooling complementary skills. Nevertheless, the authors argue that when the knowledge base of an industry is complex, expanding, and widely dispersed, the locus of innovation will be found in networks of learning, rather than in individual firms. In these situations, building external collaborations is central to updating the knowledge base of the firm. R\&D collaborations become admission tickets to the knowledge network, and vehicles for the rapid communication of new knowledge.

To test these arguments, Powell and his colleagues used a longitudinal social network analysis, with five years of data that included measures of the number of $R \& D$ ties, the diversity of ties and the network centrality of each company. They found support for their hypotheses, indicating that a firm's portfolio of alliances and resultant network position were dependent on previous network experience, and that the size of a firm was positively related with previous network centrality. Thus, the establishment of a network of collaborations in biotechnology firms seems to be a cumulative process, and the development of a central position in the network enables future growth.

In a similar vein, Liebeskind et al. (1996) also use knowledge sourcing arguments to explain research collaboration behavior in the biotechnology industry. But, in contrast to the focus on formal R\&D alliances by Powell and colleagues (1996), these authors studied informal research collaborations. They argued that, in a knowledge environment characterized by complexity and rapid change, boundary-spanning networks based on informal relations represent opportunities for sourcing scientific knowledge from external experts. 
Their analysis of the publication and patent records of two highly successful biotechnology firms revealed a myriad of research collaborations with external parties (mainly research laboratories and universities), which were not covered by either contractual or market arrangements. These collaborations did not decrease over time and did not lead to problems in appropriating knowledge, since the biotechnology firms had mainly exclusive (not shared) patents. In addition, the findings of the study also pointed to the importance of long-term employment of scientists that enabled a stable organizational context, creating conditions that were helpful for sharing knowledge.

The importance of external ties in the previous studies is consistent with the probing process identified by Brown and Eisenhardt (1997). In their multiple case study of major computing firms, the authors observed that the managers of the most successful businesses gathered information about the future in an active and externally oriented way, through the use of a wide variety of low-cost probes, including experimental products, futurists and strategic alliances. Relying on explanations from learning theory, the authors describe how these probes helped managers to gain insight into future industry trends and so effectively position their firms for the future, especially in terms of new products. They also noted the importance of integrating the knowledge from probes with current activities.

Bierly and Chakrabarti (1996) used a longitudinal analysis of 21 pharmaceutical firms across a fifteen years period to synthesize knowledge sourcing tradeoffs. The authors developed a taxonomy of knowledge strategies, based upon the four key strategic decisions concerning the knowledge development of a firm: internal vs. external sources of knowledge; radical vs. incremental knowledge evolution; depth vs. breadth of knowledge base; and speed of knowledge acquisition and application. The collective responses to these four choices form the knowledge sourcing strategies of firms. Using measures of these four factors (based on R\&D spending, patent analysis and approval of new products) and cluster analysis techniques, the authors identified four consistent strategy patterns, which they named explorers, exploiters, loners and innovators. Innovators were aggressive knowledge developers, achieving high levels of internal and 
external knowledge acquisition, focusing on both radical and incremental innovation, and applying knowledge very quickly. Loners were slow and inward oriented. They had a focused knowledge base and few external linkages. Exploiters had little internal knowledge sourcing and were essentially incremental learners, showing a high level of external linkages and a broad knowledge base. Explorers were characterized by very radical knowledge evolution and average values on the other dimensions. The authors found sustained profit differentials favoring innovators and explorers.

Tripsas (1997) found evidence of a positive impact on long-term performance of establishing external research links. In an historical analysis of the evolution of three major firms in the typesetter industry, the author found that only one company was able to survive the three stages of competence-destroying technological change that swept the industry in the $2^{\text {nd }}$ half of this century. Her analysis indicated that the successful adaptation of the firm's knowledge base depended upon the capability to source and then integrate external knowledge. This capability was developed through early investments in R\&D that led to the accumulation of absorptive capacity in a variety of technologies, and through the development of an external communication infrastructure to source the relevant knowledge. Moreover, the investments in absorptive capacity were cumulative and self-reinforcing, because initial investments did not immediately lead to better performance in integrating new knowledge. Rather, they led to more successful developments over time. The external communication infrastructure was developed through regular collaborations with experts and through knowledge scanning activities. These activities allowed firm managers to identify new technologies, unrelated to their knowledge base, which were important for the future path of technological development in the industry. Another important factor for the successful adaptation was the existence of multiple locations for R\&D activities, as opposed to having a central research laboratory. These multiple locations were a source of variety and enabled managers to cope with the overlap between different generations of technological knowledge. 
In a related study, Rosenkopf and Nerkar (1999) found that firms in the optical disk industry with few external contacts became locked into fixed paths of technological evolution. The authors analyzed the impact of a firm's technological developments on the subsequent technological evolution of the industry, using knowledge exploration strategy as the predictor variable. The authors defined four main strategies to source new knowledge: local search (building upon similar technology within the organizational boundaries), radical search (spanning both technology and firm boundaries), organizational boundary spanning and technological boundary spanning. Rosenkopf and Nerkar examined technological impact, as measured by patent citations, of the 22 firms with most patenting activity in the industry between 1971 and 1995. They found that local search (measured by extensive self-citation) was negatively correlated with impact. In contrast, the highest impact approach was organizational boundary-spanning exploration, in which managers extensively used the findings of other firms in the industry to inform their own knowledge development. The second most effective approach was radical search, whereby managers crossed both organizational and technological boundaries. Therefore, an inward learning focus was not effective for achieving technological impact.

Two recent studies provide complementary insights on knowledge sourcing. Hansen (1998) adopts an internal focus for the study of knowledge sourcing. The complex and evolving nature of knowledge and the sheer size of some firms create the need for sourcing knowledge across organizational sub-units. This situation occurs in product development activities, where relevant knowledge can be identified and shared among project teams throughout a corporation. Hansen used the speed of completion of projects as the dependent variable in a sample of 120 development projects of a large electronics firm. Using measures of network centrality and knowledge relatedness as independent variables, the author concludes that effective knowledge sourcing requires both a central position in the network of relations and the possession of related knowledge that builds absorptive capacity. Further, this central position is most effectively achieved by indirect relations, because too many direct relationships are so costly to maintain that the costs may override the potential benefits. 
Recent research by Jett (1999) focuses on the relationship between external connections for knowledge sourcing and organizational action. Using a sample of 47 SBUs in the computer, networking and telecommunications industries, the author explored the impact of different probing mechanisms on managers' ability to adapt their product portfolios to changing competitive conditions. He found that strategic alliances for the exploration of new markets enabled knowledge acquisition and fostered introduction of new products. Further, and consistent with Brown and Eisenhardt (1997), these results suggest that probes, such as futurists and exploratory products, should be well-linked to the present competitive position of firms. If the probes are too far into the future, with few links to present markets and technologies, then managers will not be able to effectively use the newly sourced knowledge to improve their firms.

Summary: Taken together, these studies and others (Allen, 1977; Katz and Tushman, 1981; Brown and Eisenhardt, 1998; McEvily and Zaheer, 1999) on knowledge sourcing suggest that external linkages are important for a variety of innovation-related outcomes such as patents, patent citations, speed of product development, quality of the product pipeline, and introduction of new products. External linkages appear to help managers become aware of the content and location of new technical knowledge, and gain insight into the trajectory of their industry. Thus, in dynamic environments, searching for, identifying, accessing, and sharing new knowledge are important activities for innovative performance. These external linkages include incentives that motivate scientists to stay connected with the larger scientific community (Henderson, 1994), formal network relationships (Powell, Koput et al., 1996; Brown and Eisenhardt, 1997; McEvily and Zaheer, 1999), exploratory products (Brown and Eisenhardt, 1997; Jett, 1999), gatekeepers (Allen, 1977; Katz and Tushman, 1981), and informal networks (Henderson and Cockburn, 1994; Liebeskind, Oliver et al., 1996; Tripsas, 1997; Rosenkopf and Nerkar, 1999). These external linkages emerge as clearly valuable in industries such as biotechnology, pharmaceuticals, and optics where knowledge is at the cutting-edge of science. More surprisingly, they are also valuable in less knowledge-intensive industries such as computing 
(Brown and Eisenhardt, 1997; Jett, 1999) and even in machine shops (McEvily and Zaheer, 1999) where they provide insights into market and technical trends. Finally, the concept of a portfolio of external knowledge sourcing activities emerges. A diverse portfolio of such activities increases opportunities for experimentation and learning (Brown and Eisenhardt, 1997), especially when the knowledge probes are low-cost and so create occasions for small failures. Such portfolios are particularly relevant when the knowledge objective is to have a broad insight into the trajectory of future product and market arenas, rather than some specific piece of cutting-edge (often technical) knowledge.

In addition, a few studies suggest that similar knowledge sourcing processes occur within corporations and can also lead to more innovation (Henderson and Cockburn, 1996; Hansen, 1998). Moreover, these processes occur in loosely coupled organizations in which business units (Hansen, 1998), R\&D facilities (Tripsas, 1997), and research programs (Henderson and Cockburn 1994) are only partially connected. Hansen (1998), for example, argues that greater connection would be too time-consuming to be advantageous, while Tripsas (1997) notes the value of retaining some randomness in research in order to enhance adaptability.

Overall, these studies are useful for understanding the linkage of internal and external knowledge sourcing with innovation-related outcomes. Yet, this research stream leaves unexamined several fundamental issues related to KBV as a theory of strategy. One such issue is the relationship between knowledge sourcing and firm performance. Only a few studies examine firm performance, and those that do rely on a variety of performance outcomes, including survival (Tripsas, 1997), growth (Powell, Koput et al., 1996), market segment dominance (Brown and Eisenhardt, 1998), and profit (Bierly and Chakrabarti, 1996). As a result, there is no cumulative demonstration of the power of KBV as a theory of strategy for any specific conception of performance. Further, the studies do not examine whether sustainable competitive advantage exists as predicted by KBV. Indeed, Roberts (1999) recently showed that competitive advantage in the pharmaceutical industry is not sustained, but rather is a series of temporary advantages. Even if sustained 
advantage were demonstrated, the research does not distinguish between whether that advantage stems from the knowledge sourcing process per se, as argued by Grant (1996a), from the knowledge gathered during the process, or from some other unexamined factors.

Finally, the research suggests time is a relevant addition to KBV thinking. For example, Tripsas (1997) found that the timing of different technological innovations forced managers to adopt complex learning strategies involving different sectors of the corporation, while Jett (1999), as well as Brown and Eisenhardt $(1997 ;$ 1998), noted that future-oriented knowledge sourcing needs to be linked with current activities in order to be effective.

\section{Internal Knowledge Transfer}

A second stream of KBV research addresses internal knowledge transfer. This research explores how knowledge transfer within an organization depends upon the characteristics of that knowledge, the sender, the recipient, and their mutual relationship. This is an important stream of research because the efficacy of knowledge transfer within organizations is a primary rationale for $\mathrm{KBV}$ as both a theory of organization (Kogut and Zander, 1992; Grant, 1996; Kogut and Zander, 1996) and a theory of strategy (Grant, 1996a).

Zander and Kogut (1995) analyzed the speed at which manufacturing capabilities related to product innovations were transferred across borders by Swedish firms. The transfer of capabilities involved knowledge codification, in which the tacit knowledge embedded in the innovations was made more explicit in order to be more easily communicated and understood by the recipients. One possible drawback of such codification is that it might also speed imitation by competitors. The authors thus analyzed the impact of knowledge characteristics and competitive environment on the speeds of both internal transfer and external imitation. They used a detailed multidimensional construct for knowledge, including codifiability, teachability, complexity, systems dependence, and product observability by competitors, based on 
previously suggested knowledge taxonomies (Rogers, 1980; Winter, 1987). The authors found that greater codifiability and teachability were associated with faster transfer, but not with faster imitation. The speed of imitation was positively related only to the knowledge spillovers among firms (mainly caused by employee turnover), and to the levels of common knowledge and competence across the industry. Other findings suggested that the pressure of competition made firms more efficient in transferring capabilities and that continuous innovation impeded imitation by competitors.

Szulanski (1996) also analyzed the transfer of knowledge within the firm. His objective was to understand the causes of stickiness in the transfer of complex best practices. Based on prior research, the author focused on four main causes of stickiness: the characteristics of the knowledge transferred, the source of knowledge, the recipient, and the context of the transfer. Using a sample of 38 technical and administrative complex best practices, encompassing a total of 122 transfers, the author found that the three most important barriers to knowledge transfer were lack of absorptive capacity of the recipient, causal ambiguity of the knowledge transferred, and difficulty in establishing personal interactions between the source and the recipient. The author also found that higher knowledge retention impeded transfer because recipients were less able to unlearn old knowledge and replace it with new. Szulanski concluded that knowledge variables, not lack of motivation or cooperation, were the primary barriers to knowledge transfer.

In contrast to Szulanski's emphasis on knowledge characteristics, Lord and Ranft (1998) found that organizational structure and incentives were significant factors affecting the effectiveness of knowledge transfer. Based on a survey of 104 market entries of multinational companies, the authors analyzed the impact of knowledge characteristics and organizational variables on the internal transfer of knowledge about local markets. They concluded that, alongside tacitness of knowledge, the organizational structure, communication mechanisms, and incentives were also significant. Specifically, they found that formal vertical reporting channels and incentive systems linked to performance were positively related to 
knowledge sharing and transfer. Moreover, knowledge sharing and transfer were positively related to divisional performance.

Athanassiou and Nigh (1999) used a social network perspective to study knowledge sharing among top management teams in 37 multinational companies based on the US. The authors showed that the top management of these companies developed advice networks for sharing tacit knowledge about international business issues. These advice networks were important mechanisms for internal coordination. Furthermore, the density of these networks, defined as the ratio of advice-seeking relationships to the total possible relationships, was shaped by the international strategy of the firm. A more extensive international strategy and a higher inter-dependence of subsidiaries' activities increased the density of the network. The formal governance mechanism of the subsidiaries (i.e., wholly owned and majority-owned vs. minority participation) surprisingly had no significant relationship with the density of advice networks. This latter result suggests that the governance mechanism of subsidiaries does not change the need for tacit knowledge exchange through advice networks.

Gupta and Govindarajan (2000) also analyzed inter-firm knowledge flows across 374 subsidiaries within 75 multinational corporations in a very comprehensive study of internal knowledge transfer. Their independent variables included the strategic value of the knowledge, motivation of the source, motivation and absorptive capacity of the recipient, and communication channels, as measured in the transfer of seven types of procedural knowledge (i.e., know how). The authors separately analyzed knowledge transfer horizontally among peer subsidiaries and hierarchically with the parent. They found that knowledge flow from the parent to subsidiaries was the most pervasive type of internal knowledge transfer. Further, the communication channel (as measured by formal integrative mechanisms and socialization), absorptive capacity, and strategic value of the knowledge facilitated knowledge transfer, while incentives to share knowledge had no effect. 
Hargadon (1998) provides interesting insights into how organizational structure and culture can facilitate knowledge transfer within the firm. The author developed case studies of firms that act as knowledge brokers (e.g., product design firms, management consultants and consulting sub-units within large corporations). Knowledge brokers place themselves in a network of clients that cuts across different industries and technology areas, and are thus able to link problems in one area with their knowledge of solutions from other areas. These firms thus rely extensively on internal transfers of knowledge to operate successfully. Hargadon found that knowledge brokers used fluid project teams. Further, their organizational structure mimicked the diverse and relatively disconnected domains in which they operated. Within knowledge broker firms, individuals adhered to norms that required sharing knowledge freely with other organizational members. Hargadon found that the most important barriers to knowledge transfer were employee turnover, organizational size, and increasing demands on individual time and individual efficiency.

Similarly, Brown and Eisenhardt (1998) examined inter-firm cooperation (including knowledge transfer) in their study of 12 major computing firms. They found that more effective firms limited knowledge transfer to the most strategically valuable information, rather than all possible information. The managers of these firms accomplished this by having regular meetings among business unit heads to share opportunities to collaborate, and then letting these business leaders choose whether or not to collaborate. The former created the social bonds and information necessary for collaboration to occur, while the latter helped to ensure that the best opportunities were chosen. Thus, in the best performing firms, senior executives set the context for collaboration among businesses. In less effective firms, senior executives either ignored cross-business collaboration or forced collaboration from the top. Finally, in related work, Eisenhardt and Galunic (2000) indicated that, when knowledge was transferred effectively, business unit heads were rewarded for their own business' success, not for collaboration per se. 
In a study of 120 development projects in a large electronics firm, Hansen (1999) addressed the different relationship requirements for the transfer of simple vs. complex knowledge. Speed of project completion was the dependent variable while the complexity of knowledge to be transferred (measured in terms of tacitness and systems dependence) and strength of the relationships of the project team (measured by tie weakness) were the independent variables. The author found that weak ties favor knowledge search but impede the transfer of complex knowledge, as compared with strong ties. Based on these findings, Hansen asserted that effective organizational design should consider the type of knowledge likely to flow within the organization. When knowledge is simple and easily transmitted, weak ties are likely to solve the problem of obtaining knowledge. When knowledge is more complex, effective internal transfer is more challenging, and requires strong ties in the form of formal mechanisms and frequent interaction.

Summary: Taken together, many of these studies indicate that knowledge characteristics affect the efficacy of internal knowledge transfer. These characteristics include tacitness (Zander and Kogut, 1995; Lord and Ranft, 1998), causal ambiguity (Szulanski, 1996), and complexity (Hansen, 1998), which impede knowledge transfer, and strategic value (Brown and Eisenhardt, 1998; Gupta and Govindarajan, 2000), which enhances knowledge transfer.

These studies also indicate that the relationship between the sender and recipient is crucial for knowledge transfer. When the sender and recipient have difficulty in establishing interpersonal interactions (Szulanski, 1996) such as when they are distant, knowledge transfer is impaired. In contrast, when integrative mechanisms such as teams, liaisons, informal social networks, norms for collaboration, and formal meetings exist (e.g., Hargadon, 1998; Gupta and Govindarajan, 2000; Eisenhardt and Galunic, 2000), knowledge transfer is facilitated. Overall, appropriate organizational structure and culture can ease knowledge transfer.

Moreover, several studies indicate an interaction between knowledge characteristics and the relationship between sender and recipient. If the transfer is more difficult because of complex knowledge (Hansen, 
1999) or knowledge that requires significant local adaptation (Hargadon, 1998), then the relationship between sender and recipient must be stronger with frequent and personal face-to-face interaction s in order for effective knowledge transfer to occur. In addition, the greater the absorptive capacity of the recipient, the more easily knowledge is transferred (Szulanski, 1996; Gupta and Govindarajan, 2000).

The most controversial aspect of the empirical studies surrounds the role of incentives for the sender and the related top-down enforcement of knowledge transfer. Lord and Ranft (1998) found that incentives and vertical reporting relationships enhanced transfer of knowledge about international market entry and improved performance. Gupta and Govindarjan (2000) found that vertical reporting did enhance knowledge transfer, but incentives did not. Finally, Eisenhardt and colleagues (Brown and Eisenhardt, 1998; Eisenhardt and Galunic, 2000) indicate that senior executives in the most effective firms create a collaborative context through culture and organizational structure, but they do not force or even reward collaboration per se.

These diverse findings suggest that when knowledge is relatively simple and static, top-down enforcement and incentives improve knowledge transfer by dealing with motivation issues. When that knowledge is also strategically valuable, transfer will enhance performance (Lord and Ranft, 1998). In contrast, when knowledge is complex, knowledge and relationship characteristics dominate the motivational issues in knowledge transfer (Szulanski, 1996). Further, when knowledge is varied and changing, context setting activities, through organizational structures and cultural norms that make managers aware of knowledge transfer opportunities, are effective, but incentives to collaborate are not. Such incentives may not only be ineffective in knowledge transfer (Gupta and Govindarajan, 2000), but they may also negatively impact performance by encouraging managers to waste time and resources transferring non-strategic knowledge (Eisenhardt and Galunic, 2000).

In summary, these studies are very useful for understanding internal knowledge transfer. But they are less helpful in dealing with the performance issues that are at the heart of strategy. Many of these studies 
implicitly link knowledge transfer and performance. Nevertheless, both Gupta and Govindarajan (2000) and Brown and Eisenhardt (1998) argue that the strategic value of the knowledge is crucial to whether improved performance is actually achieved. These authors suggest that the managers of effective firms should concentrate their efforts on transferring only the most strategically valuable knowledge. In fact, less knowledge transfer can be more effective than more transfer, especially in high-velocity environments where the time of managers is so limited (Eisenhardt and Galunic, 2000). Further, only two studies (Brown and Eisenhardt, 1998; Lord and Ranft, 1998) actually measured performance.

More broadly, these studies, like those on knowledge sourcing, do not deal with important aspects of KBV theory. They do not indicate whether knowledge transfer results in sustained or even temporary competitive advantage. Similarly, they do not address whether advantage derives from the knowledge transfer process, the knowledge itself, or both. Finally, the theoretical rhetoric of KBV asserts that knowledge is the most strategically important resource. Yet it is unclear from these studies what constitutes valuable knowledge, when to transfer it, or whether extensive internal knowledge transfer is strategically wise.

\section{External Knowledge Transfer}

A third stream of research addresses knowledge transfer across firm boundaries through alliances and acquisitions. This stream is significant because it sheds light on several fundamental theoretical assertions of KBV as a theory of strategy and of organization, namely that effective knowledge transfer is a source of sustained competitive advantage and that it is more effectively accomplished within organizations rather than markets.

Several studies address specifically how organizations transfer knowledge through their participation in alliances. Lane and Lubatkin (1998) explored the impact of partner characteristics on the acquisition of new knowledge in the form of new skills and capabilities. Their study examined $31 \mathrm{R} \& \mathrm{D}$ alliances between 
pharmaceutical and biotechnology companies, where the pharmaceutical firm is the learning entity and the biotechnology firm is the teacher. In their view, learning tacit and embedded knowledge requires absorptive capacity in the recipient firm, which is relative in that it depends on the teacher firm. In an unusual conception, the authors measured relative absorptive capacity by a three-dimensional construct, using indicators of knowledge overlap, similarity in knowledge processing systems, and similarity of commercial logic. The dependent variable of knowledge acquisition was measured by a panel of industry experts who assessed how much the recipient firms had learned in terms of new capabilities and knowledge spillover. The authors found that the similarity of basic knowledge was positively related to learning, while the similarity of specialized knowledge was negatively correlated. Presumably in the latter case, the knowledge of the sender was too similar to be of value to the recipient. The results for similarities of knowledge processing systems (measured by the degree of formalization and centralization of the organizational structure) were mixed. Similarity in lower level management and research structures was positively related to learning, while similarity in top management and business decision structures was negatively related. Finally, the authors found that the sharing of research communities was positively related to knowledge transfer knowledge. Overall, the results validate that knowledge transfer is dependent on measures of distance or dissimilarity to the partner firm.

In a similar vein, Inkpen and Dinur (1998) found that effective transfer of knowledge exhibited an inverse relationship between tacitness of knowledge and the organizational level at which the transfer took place. Based on a longitudinal analysis of five case studies of North-American-based automotive joint ventures (JV) between U.S. and Japanese companies, the authors analyzed the processes by which parent companies accessed and transferred the knowledge created in the context of the joint venture. The research results suggest that individuals are the best agents for the transfer of highly tacit knowledge, when compared to groups or higher organization levels. It also suggests that the transfer of tacit knowledge demands a high level of individual interaction, through regular meetings, temporary sharing of human resources and frequent visits to manufacturing facilities. Moreover, there were indications that managers who focus their 
attention on acquiring only explicit knowledge undervalued the relationship potential by neglecting tacit knowledge-based opportunities. Finally, there was a positive relation between the transfer of tacit strategic knowledge and the development of strategic relationships between the firms.

Similarly, Simonin (1999) studied the effects of the characteristics of knowledge, sender, and recipientsender relationship on knowledge transfer. His sample included 147 alliances executed by U.S. multinationals, with data provided by single informants. The results indicate that tacitness and complexity of knowledge lowered knowledge transfer, as did cultural and organizational distance between the two firms. These factors, however, were all mediated by knowledge ambiguity, which emerged as the principal factor affecting knowledge transfer. The author also replicated his previous finding (Simonin, 1997) that collaborative know-how from past alliances improved knowledge transfer.

The next two studies offer compelling insights into how the knowledge base of alliance partners changes over time. In one of the studies, Mowery et al. (1996) used data on patent citations to trace the changes in technological portfolio of partner firms as a consequence of alliances. Using a sample of 792 alliances including at least one US firm, the authors had several findings that were consistent with those of others. That is, strong ties (i.e., equity joint ventures) were more likely to be used to transfer complex capabilities than weak ties (i.e., contractbased alliances). Further, strong ties (i.e., bilateral contracts) were more effective than weaker ties (i.e., unilateral contracts) for knowledge transfer. In addition, alliances between two US partners and between partners with experience in related technological areas (i.e., greater senderrecipient similarity) resulted in greater knowledge transfer.

The most intriguing result of the study, however, was that the partners in a substantial subset of the alliances exhibited technological divergence. This sharply contrasts with the technological convergence that would be expected in alliances geared toward knowledge acquisition and capabilities transfer. So, while knowledge transfer was one outcome of alliances, so too was the coevolution of the partners into 
increasingly unique roles. In this latter situation, knowledge transfer evolved into knowledge integration, while the overall system of relationships came to resemble a complex adaptive system based on partially connected and specialized partners (Anderson, 1999; Eisenhardt and Bhatia, 2000).

A similar coevolution among alliance partners into increasingly specialized knowledge positions also appeared in a longitudinal analysis of three inter-firm alliance networks in the Italian packaging machine industry (Lorenzoni and Lipparini, 1999). The firms developed networks of inter-firm relationships around the specialized knowledge necessary to assemble and supply packaging machines. These machines had many interdependent groups and parts, which required extensive mutual adjustment and inter-firm coordination. Comparing firm strategies in 1988 and 1995, the authors found evidence that managers had narrowed their firm's scope of technological competence and increased their reliance on a network of longterm relationships with other suppliers as the best way to pursue product quality and flexibility. Using codesign and co-manufacturing processes, managers developed relational capabilities with one another across their firms. They further exchanged goods and knowledge on a daily-basis, which allowed their firms to increasingly develop specific competencies. Trust developed between partners, which further eased problems of coordination and control of the exchanges while decisions began to transcend considerations of short-term economic efficiency. Similar to the firms in Mowery et al. (1996), these firms coevolved into networks of more specialized organizations that came to resemble complex adaptive systems. Not surprisingly then, the emergent networks created increased capacity to adapt to environmental change and so enabled firm managers more effectively keep pace with technological developments within the industry.

Using a different lens on knowledge transfer, Almeida (1996) examined whether and how managers could overcome impediments in alliance relationships. Specifically, he studied foreign semiconductor multinationals whose managers established plants in the US in order to take advantage of the regional knowledge-sharing networks. Using patent citations to analyze inter-firm knowledge flows, the author found that these firms learned more than similar domestic firms. The explanation for this success in external 
knowledge transfer was that firm managers were very motivated to learn and did so by joining local knowledge networks, mainly through hiring local employees and using local suppliers. That is, the "liability of foreignness" that creates dissimilarity can be overcome by the motivation to learn locally using mechanisms that reduce the "distance" between partners in a knowledge transfer. In addition, these foreign firms also contributed more to local knowledge, suggesting that knowledge transfer is rarely one-way.

A different line of research focuses on acquisitions as a means for external knowledge transfer. Ranft and Zeithmal (1997) argued that the recent wave of acquisitions in high-technology industries has the goal of expanding the knowledge base of the acquiring companies. Thus, long-term value creation from this kind of acquisition depends on knowledge transfer between firms. Yet, this knowledge can be difficult to extract from acquired firms because it is often tacit and embedded within the organization and within key individuals who may leave due to the acquisition. The authors analyzed the process of post-acquisition knowledge transfer in 75 high-tech acquisitions during 1994-95. Overall, they found that a greater tacitness of knowledge had a negative impact on the transfer of knowledge, Additionally, higher levels of communication increased the transfer of all types of knowledge, while higher autonomy of the acquired firm's personnel and longer acquisition integration periods reduced knowledge transfer.

Using the same sample of acquisitions, Ranft and Lord (1998) explored the impact of employee retention (middle managers, $R \& D$ people, engineers, and salespeople) on knowledge transfer. These employees often possess the tacit knowledge of the firm that is being acquired. The authors found that the retention of key employees is positively correlated with knowledge transfer. They also established that post-acquisition autonomy, corporate commitment from the acquiring firm, and a high relative standing position for the acquired personnel, were important factors in the retention of key employees. Surprisingly, the effect of financial incentives was not significant, which suggests that, when dealing with highly skilled or experienced people, material incentives are not important when compared to other factors related to work definition or working environment. 
Summary: Taken together, these and other studies of external knowledge transfer (e.g., Simonin, 1997; Capron, 1999; Dyer, 1999; Kale, Dyer et al., 1999) indicate that knowledge transfer is affected by knowledge characteristics and by the relationship between the sender and the recipient. As such, these studies replicate the studies of internal knowledge transfer. In particular, the tacitness (Inkpen and Dinur, 1998; Ranft and Lord, 1998; Simonin, 1999), complexity, and ambiguity of knowledge (Simonin, 1999) reduced knowledge transfer. Knowledge that was too similar and so lacked strategic value also led to less knowledge transfer (Lane and Lubatkin, 1998).

The relationship between the sender and recipient also affected knowledge transfer as it did in the internal knowledge transfer literature. Similarities in general knowledge base (Mowery, Oxley et al., 1996; Lane and Lubatkin, 1998), organizational structures (Simonin, 1999) including similar lower level management and research structures (Lane and Lubatkin, 1998), organizational culture (Mowery, Oxley et al., 1996; Simonin, 1999), and strategy (Inkpen and Dinur, 1998) improved knowledge transfer. Further, integrative mechanisms such as meetings, personnel exchange, bilateral contracts, and personal interaction were effective in overcoming the challenges of transferring tacit and/or complex knowledge (Mowery, Oxley et al., 1996; Inkpen and Dinur, 1998) and the organizational differences (Almeida, 1996; Ranft and Lord, 1998). Conversely, structural and procedural barriers (Dyer, 1999) can inhibit knowledge transfer in both alliances and acquisitions (Capron, 1999). Firms that have translated their experience into know-how (Simonin, 1997; Simonin, 1999) that is embedded in organizational structures (Kale, Dyer et al., 1999) have more successful knowledge transfers. Finally, as in the case of internal knowledge transfer, stronger ties are needed to transfer more complex knowledge (Mowery et al., 1996).

But, the research on external knowledge also suggests some twists when compared with the internal knowledge transfer literature. One such twist is the emergence of specialization among alliance partners (Mowery, Oxley et al., 1996; Lorenzoni and Lipparini, 1999) such that relationships that may have begun as 
knowledge transfers become ones of knowledge access and integration. This divergence and specialization suggests that alliances can be a way to gain access to knowledge (Powell, Koput et al., 1996), without transfer of that knowledge into the organization. Further, it suggests that networks of alliance relationships can become complex adaptive systems in which different firms coevolve into specialized roles to form highly adaptive networks. Since limited evidence (Brown and Eisenhardt, 1998; Eisenhardt and Galunic, 2000) indicates that the emergence of specialized, coevolving actors can also occur inside corporations, comparison of this phenomenon inside and outside organizations is an intriguing research opportunity.

A second twist from the internal transfer literature is that knowledge extrication poses difficult challenges in external knowledge transfer sit uations. For example, a dilemma of knowledge transfer via alliances and acquisitions is that very often the desired knowledge is highly tacit, deeply embedded in individual experiences and organizational context, and co-mingled with other knowledge and resources that are not of interest. Successful knowledge transfer, therefore, requires a focus on the interactions of individuals and the preservation of organizational context (Inkpen and Dinur, 1998; Ranft and Lord, 1998). And, especially in the case of acquisitions, there is a further dilemma. Retention of key employees improves knowledge transfer (Ranft and Lord, 1998), but the high degree of autonomy for the acquired firm that leads to this retention of key employees (Ranft and Lord, 1998) lowers knowledge transfer (Ranft and Zeithaml, 1997). The implication of this research is that extrication of externally located knowledge can be complex and difficult to accomplish, especially in the case of acquisitions (see also Capron, 1999; Graebner, 1999).

Finally, this research stream does not sharply answer the critical questions of whether external knowledge transfer is either easier or qualitatively different from internal knowledge transfer. Yet, a primary of assumption of KBV as a theory of organization (Kogut and Zander, 1992; Grant, 1996) is that knowledge transfer is facilitated within organizations as compared with markets. Certainly, the two knowledge transfer research streams indicate that similarities in organizational structure and culture, which seem more probable within organizations, should ease transfer. The external knowledge transfer stream also suggests that 
acquisitions pose particular challenges. But, we found no studies that compared intra- and interorganizational knowledge transfer per se. Further, integrative mechanisms such as meetings and personal interaction may overcome the advantages of organizations for knowledge transfer, where such advantages exist (Almeida, 1996). In terms of KBV as a theory of strategy, the current research does not address whether the source of advantage is a more effective external knowledge transfer process per se, or if the knowledge itself creates advantage, or whether that advantage is sustained or temporary.

\section{Knowledge Integration}

A fourth stream of research focuses on how specialized knowledge is integrated from different sources to generate new knowledge or to apply that knowledge to the creation of new products and services. In particular, much of this research centers on how individuals from different communities-of-practice integrate their specialized knowledge. As such, it emphasizes the micro-processes of interaction, mostly within organizations, that enable the integration of knowledge. This stream of research is especially relevant to $\mathrm{KBV}$ because of the assertion that knowledge integration (especially integration of the tacit knowledge that is held by individuals) is a primary source of superiority of firms over markets and a major way in which competitive advantage is achieved (e.g., Grant, 1996).

Eisenhardt (1989) conducted an inductive study on the strategic decision-making processes of top management teams in the computer industry. These teams integrated their different functional and personal perspectives to achieve group decisions regarding crucial strategic issues such as major alliance formation and financing. The author studied the process by which speed and quality were achieved in strategic decisions. She found that the extensive use of concrete and real-time information, as opposed to abstract and accounting-based information, and the simultaneous consideration of multiple alternatives, accelerated decision speed and linked to higher firm performance. She also found that a specific procedure for conflict 
resolution - consensus with qualific ation - was very effective for achieving rapid and high-quality decisions.

Dougherty (1992) also focused on knowledge integration. This work was motivated by the observation that product innovators often fail to link technological and market issues, and to collaborate across departments. The author attempted to explain these knowledge integration problems through an analysis of 18 case studies of product innovation in large computer/communications and chemical firms. Based on extensive interviews, the author found that different departmental "thought worlds" (i.e., the knowledge that people from each functional area have about product innovation) systematically varied. Moreover, the systems of meaning on issues like the perspective on the future, or the identification of the critical aspects of the innovation process, also varied across thought worlds. This meant that people "not only know different things, but also know things differently", thus creating difficulties in knowledge integration.

These difficulties were exacerbated by many established routines (job descriptions, criteria for markettechnology research and standards definition) that encouraged the separation of thought worlds. Successful innovators broke away from these established routines and created new social orders based on mutually adaptive interactions in which knowledge developed as the work unfolded. In particular, the successful innovators overcame the barriers of different thought worlds by creating a customer focus, made tangible and realistic through concrete experiences such as joint participation in focus groups, customer visits, and technology audits. Structural solutions like liaison people or boundary-spanning roles were not enough to ensure the bridging of thought worlds.

In an ethnographic study at the largest product design firm in the U.S., Hargadon and Sutton (1997) described how the firm routinely innovated by integrating and recombining knowledge across several industries. The designers of the firm were coached to learn about technological and design solutions in different areas and industries, and to keep available artifacts and archives exemplifying those solutions. Some of these artifacts were kept at the organizational level and translated into a collection of concrete 
solutions to possible design problems, representing a very tangible form of organizational knowledge. The culture of the firm also fostered knowledge integration among the designers through the use of informal discussions and e-mail requests to share knowledge and link solutions to problems. Knowledge sharing and integration were also institutionalized by frequent brainstorming sessions where a particular problem would be addressed and possible solutions freely discussed by designers, with the aid of drawings and tangible representations. Drawing analogies between past solutions and the present problem was also an important element of these sessions, and a key mechanism of knowledge integration as well.

In a recent ethnographic study of a production floor, Bechky (1999) also addressed knowledge integration across thought worlds. The author studied three different communities-of-practice (engineers, technicians and assemblers) whose members collaborated on the development and production of new machines. The different understandings of these communities were based on distinct work practices, ranging from the schematic understanding of the engineers to the spatio-temporal understanding of the assemblers. Their language reflected the different work practices and created communication problems between the communities. Status differences made communication more difficult, especially the upstream feedback from the production floor to the drawing board. Language problems arose in the course of interactions, mainly by attributing different meanings to the same word or using different words to represent the same objects. Interruptions of the production floor activities, due to failures, created occasions for interaction across occupations During these interruptions, shared understanding and related knowledge integration was developed by translation (through the brokering of technicians) and by tangible examples and physical objects. These concrete problems were thus effective mechanisms for individuals in different communities to learn from each other.

The above account has striking similarities with a recent description of knowledge integration among firms in the U.S. automobile industry (Helper, MacDuffie et al., 1999). Based on a survey of suppliers, the authors found evidence of an extraordinary increase in interaction between customers and key suppliers 
(named "super suppliers" or first-tier suppliers), through different means of communication, on a daily or weekly basis. The greatest increase occurred in contacts geared to "joint efforts to improve the product or processes", which indicates an effort to integrate knowledge across firms in the context of concrete issues and tangible processes.

Finally, in an experimental setting, Okhuysen and Eisenhardt (2000) analyzed the impact of simple formal interventions on knowledge integration in small groups. Interventions that increased group interactions (e.g., directions to manage time and question others) were effective in improving knowledge integration, while, surprisingly, other interventions that created a self-focus on knowledge (e.g., directions to share information) were not effective. The positive impact in knowledge integration was triggered by clusters of attention switches caused by the intervention, that providing opportunities for interactions that changed the group's approach to knowledge integration. This research demonstrates empirically the relevance of a distinction between knowledge sharing of one's information and knowledge integration by which individuals combine their information in order to create new meanings. This research also suggests how simple structures and interventions can improve knowledge integration and subsequent task performance.

Summary: Overall, these studies highlight the importance of concrete and tangible expressions of knowledge, especially in the context of actually solving real problems, for knowledge integration within and across firms. Such expression of knowledge in realistic contexts appear to be an important way to overcome the challenges of knowledge integration created by the existence of different knowledge, different modes of knowing, and different ways of expressing knowledge. The extensive use of artifacts (Hargadon and Sutton, 1997), realtime operating information (as opposed to abstract accounting data) (Eisenhardt, 1989), joint customer visits (Dougherty, 1992), specific alternatives (Eisenhardt, 1989; Hargadon and Sutton, 1997), and tangible representations of problems (Hargadon and Sutton, 1997; Bechky, 1999) helped in breaking down communication barriers while increasing analogic thinking and related understanding, so that knowledge integration became more effective. 
In addition, the work by Dougherty (1992) suggests that established routines and rules, such as formal and complicated standards, job descriptions, and criteria for market research, can create barriers to knowledge integration across communities. Yet, several of the other studies include examples of routines and rules that promote knowledge integration, like consensus with qualification, consideration of multiple alternatives (Eisenhardt, 1989), formal interventions (Okhuysen and Eisenhardt, 2000) and brainstorming sessions (Hargadon and Sutton, 1997). Obviously then, rules and routines have enormous power both to improve and impede knowledge integration. The more effective rules and routines appear to encourage and legitimate airing different points of view, while leaving leeway for individual interpretation and creative implementation. In contrast, the less effective rules were self-focused or locked behavior into defined procedures, many of which quickly become obsolete and created further barriers among disparate individuals.

Finally, with a few exceptions (e.g., Eisenhardt, 1989), the research on knowledge integration lies outside the traditional strategy literature despite the theoretical importance of knowledge integration to KBV arguments (Grant, 1996). Not surprisingly then, this research stream does not address key issues of strategy such as the nature of competitive advantage and implications for firm performance.

\section{Discussion}

We began this chapter by asking if the knowledge-based view (KBV) provides distinctive insights about the sources of superior performance, and could thus be considered a new theory of strategy and perhaps of organization as well. In addressing these and related questions, we discussed varying views of knowledge, several streams of thinking that underlie KBV, and the variety of theoretical statements regarding what KBV might be. We then reviewed four streams of empirical research that relate to major knowledge processes. Based on this analysis, we have several observations. 
First, our review indicates divergence on the meaning of knowledge between the theoretical and the empirical literatures. On the one hand, the theoretical literature contains several rich conceptions of knowledge. These include articulating knowledge-based thinking in terms of different kinds of knowing (Cook and Brown, 1999), spiral theories linking individual and organizational knowledge (Nonaka and Takeuchi, 1995), and understanding knowledge in terms of emergence and identity (Kogut and Zander, 1996; Spender, 1996). On the other hand, the empirical literature, particularly within the strategy field, has largely focused on one, relatively simplistic conception of 'knowledge as resource'. Although there are other conceptions of knowledge within the empirical literature, they (see Lam, 1997 for an exception), they exist mostly outside of the strategy field (e.g., Hargadon, 1998; Bechky, 1999).

Second, our review reveals that knowledge sourcing leads to more innovative outcomes when managers engage in a portfolio of activities, both inside and outside the corporation, to gain knowledge. These activities include rewarding scientists for publication (Henderson and Cockburn, 1994), formal network relationships (Powell, Koput et al., 1996), and exploratory products (Brown and Eisenhardt, 1997). In other words, a portfolio of externally oriented connections leads to more innovation.

Third, our review suggests significant similarity between internal and external knowledge transfer processes. Characteristics of knowledge like tacitness (Zander and Kogut, 1995; Lord and Ranft, 1998), complexity (Hansen, 1999; Simonin, 1999), and ambiguity (Szulanski, 1996) affect knowledge transfer both within and across organizations. Similarly, the recipient's absorptive capacity (Gupta and Govindarajan, 2000), the sender's motivation, and the distance between sender and recipient (Szulanski, 1996) also influence the efficacy of knowledge transfer, both inside and outside the firm. These results imply that organizations may not be unique in their ability to efficiently transfer knowledge. 
Fourth, the literature suggests a subtle interplay between knowledge per se and the structures that are the conduit through which knowledge flows. In some situations, structures can clearly impede knowledge flow (Dougherty, 1992; Dyer, 1999). Yet, structures such as teams, liaisons, formal interventions, and meetings can also improve knowledge flow within and across organizations (Almeida, 1996; Brown and Eisenhardt, 1998; Hargadon, 1998; Inkpen and Dinur, 1998, Okhuysen and Eisenhardt 2000). At a more basic level, loosely linked organizational structure is related to innovative knowledge flows and adaptive organizational outcomes (Henderson and Cockburn, 1994; Tripsas, 1997; Brown and Eisenhardt, 1998; Hansen, 1999). Over time, organizations may coevolve into more distinctly specialist roles within systems of knowledge integration among organizations (Mowery et al, 1996; Lorenzoni and Lipparini, 1999). Overall, this suggests that organizations and groups of organizations become complex adaptive systems (i.e., organized into loosely linked systems of unique knowledge specialists), and when they do so, they become collectively more innovative, adaptive, and ultimately successful in dynamic markets.

Finally, our review sheds light on the question of whether KBV is a new theory of strategy, a new theory of organization, or both. In our view, it is none of these. The basic tenets of KBV have not received much empirical examination. As we noted earlier, the theory has not been tested with regard to the nature of competitive advantage (temporary vs. sustained) or the source of that advantage (knowledge vs. knowledge processes). Even the normative implications of the theory have received little empirical examination. Rather, the typical approach is to measure performance indirectly by using a mediating dependent variable such as speed of knowledge transfer (Zander and Kogut, 1995; Szulanski, 1996), learning (Lane and Lubatkin 1996), or number of patents (Henderson and Cockburn, 1994). While such measures are suggestive of performance, they are not actually measures of performance that can yield insights into the nature of competitive advantage, the source of that advantage, or whether that advantage exists at all.

More significant, $\mathrm{KBV}$ as a theory of strategy rests on the assumption that knowledge is the most important resource. While this assumption has surface appeal, there appears to be little, if any, empirical evidence that 
this assumption is true. Indeed, several authors (Eisenhardt and Galunic, 2000; Gupta and Govindarajan, 2000) suggest that it is crucial to consider the strategic value of knowledge. In other words, not all knowledge is equally valuable. More knowledge sourcing, transfer, and even integration is not necessarily advantageous unless the knowledge is strategically valuable. Others (e.g., Chacar and Coff, 2000) find that the returns to knowledge may go to the individuals who possess that knowledge, not to the firm.

Perhaps most problematic is that the strategic logic of KBV is a special case of the resource-based view. That is, when knowle dge is conceptualized as a resource that can be acquired, transferred, and integrated, the strategic logic is simply an extension of the resource-based view of strategy in general, and the dynamic capabilities approach in particular. Therefore, KBV is simply not a new view of strategy.

Finally, KBV is also not as yet a new theory of organization. From a theoretical standpoint, it is unclear exactly what the organization is, or why organizations are likely to be more effective than markets in the execution of various knowledge processes. As we noted in the empirical review, internal and external knowledge transfer seem quite similar, suggesting that knowledge processes may not uniquely distinguish organizations. More significant, a growing number of authors (e.g., Blackler, 1993; Kogut and Zander, 1996; Spender, 1996; Von_Krogh, Roos et al., 1998; Patriotta and Pettigrew, 1999), especially from the fields of sociology, cognitive psychology and critical European perspectives, take exception to the assumption of knowledge as a resource, and the view of organizations that follows from that assumption. They regard such thinking as mechanical and reductionist. These authors prefer to frame knowledge as a process of knowing, and see organizations as complex activity systems of knowledge emergence and application. Thus, KBV lacks a sharply defined and consensus set of assumptions about organizations and knowledge.

So what is KBV? The extensive empirical literature within the strategy field reveals important insights about fundamental knowledge processes that are related to strategic phenomena, ranging from alliances and 
acquisitions to strategic decision-making and innovation. In other words, KBV offers a wide-range of important insights that are relevant for improved understanding of many strategic processes. But, it is not as yet a new theory of strategy or of organization.

\section{A Research Agenda for the Knowledge-Based View}

Knowledge-based thinking is still in its early stages, and may yet become a theory of strategy and of organization. In order to accelerate the development of $\mathrm{KBV}$, we offer three broad suggestions for future research.

\section{Develop Consistent Knowledge Taxonomies and Constructs}

Research on KBV rests on fundamental inconsistencies in how knowledge is conceptualized and measured, beyond the commonly accepted distinction between tacit and explicit knowledge. Even this distinction is troublesome since some researchers believe that tacit knowledge can be made more explicit through a process of codification (Kogut and Zander, 1992) while others see tacit and explicit knowledge as essentially distinct and complementary forms of knowledge (Cook and Brown, 1999).

The studies reviewed in this chapter illustrate these inconsistencies. The most cited framework for knowledge was proposed by Winter (1987) and was based on earlier work on the diffusion of innovations (Rogers, 1980). In this taxonomy, knowledge is classified along four dimensions: tacitness, complexity, systems dependence and observability. Tacitness is further divided into teachability and codifiability. Some authors used this detailed taxonomy (Zander and Kogut, 1995) while others just focused on an aggregate construct like ambiguity (Szulanski, 1996). Still others defined tacitness using codifiability, teachability and 
complexity constructs (Lord and Ranft, 1998). Others relied on a very aggregate construct of complexity, based on measures of codifiability and systems dependence (Hansen, 1999).

This inconsistent conceptualization and measurement of knowledge creates confusion, especially when trying to compare findings across different studies, and so retards the accretion of understanding about KBV. Therefore, a useful future direction for research would center on developing a consistent classification for knowledge constructs. From our review of the empirical literature, we suggest that such knowledge taxonomy should at least include measures of codifiability (the extent to which the knowledge can be articulated) and complexity (number of interrehted elements that compose the knowledge). Additional dimensions of knowledge could be used in specific studies. Simonin (1999), for example, develops and applies a comprehensive taxonomy of knowledge in the context of knowledge transfer in strategic alliances.

In terms of improved constructs for knowledge processes, the distinction made by Hansen (1999) between knowledge transfer and sharing, and the one made by Okhuysen and Eisenhardt (2000) between knowledge sharing and integration, are examples of how a more precise definition of knowledge processes can lead to new and interesting empirical findings.

\section{Bridge Knowledge and Knowing Perspectives}

A second direction for future research is to pull together the varied views of knowledge to create a more complete understanding. As we noted earlier, an emphasis on the process of knowing, as opposed to knowledge as a resource, has been the focus of the critical perspective towards the dominant KBV approach (Blackler, 1995; Spender, 1996; Tsoukas, 1996). If KBV is to develop beyond being just an extension of $\mathrm{RBV}$, then its proponents need to incorporate the insights from this critical approach, and so bridge the two 
theoretical frameworks to create a more complete and accurate picture of the role of knowledge and knowing in organizations.

A recent paper by Cook and Brown (1999) proposes an epistemological template on which such an integrated knowledge-based view can be developed. The authors argue that tacit and explicit knowledge are distinct forms of knowledge. While tacit knowledge might be useful to generate explicit knowledge and vice-versa, one type of knowledge cannot be converted into another. The authors also argue that individual and group knowledge are distinct forms of knowledge. An example of explicit group knowledge is reflected in the "war stories of communities of practice" (Orr, 1996), while an example of tacit group knowledge might be the different knowledge structures identified by Lam (1997) in an engineering setting. Combining these two dimensions of knowledge gives a $2 * 2$ matrix that defines four distinct types of knowledge. These types of knowledge are linked to the processes of knowing, which are deeply related to the interaction of individuals with the world. The authors argue that it is through the interplay of knowledge and knowing that innovation takes places in organizations (Cook and Brown, 1999).

The bridging of knowledge and knowing implies that less focus should be given to the idea of knowledge transfer (moving a piece of knowledge from one place to another) while more focus should go to knowledge integration processes, in which the development of meaning and the creation of new knowledge occurs through individual interactions and is affected by social contexts (Galunic and Rodan, 1998). In a similar vein, another useful research direction is to continue to develop the perspective of social identity within the organization, and study its relation to the effectiveness of knowledge processes (Kogut and Zander, 1996; Spender, 1996; Kogut, 2000). Such theoretical development may prove to be essential to frame KBV as a theory of organization.

\section{Enrich KBV with Ideas from Other Fields of Research}


A third research direction centers on expanding the intellectual base of KBV. In our view, KBV researchers have neglected the potential insights related to knowledge that are being developed in other fields such as social psychology, sociology, and evolutionary biology. Relating these insights to KBV might help in further developing the organizational and strategic logic of KBV.

In social psychology, for example, Weick and Roberts (1993) focused on the concept of collective mind. This concept raises cognition to a higher level of analysis and helps to explain why some organizations are extremely reliable in face of great complexity. Another example is the concept of transactive memory (Moreland, Argote et al., 1996) that suggests the importance of distinguishing transactive knowledge (who knows what) from declarative (what is known). Such a distinction might prove valuable in understanding knowledge integration and transfer processes. Transactive memory is often more crucial to effective knowledge transfer than the actual transfer itself (Hargadon, 1998). A third example is the social psychology surrounding interruptions and breakdowns in daily working routines as an instance for knowledge creation (Bechky, 1999; Patriotta and Pettigrew, 1999).

Drawing from sociology, the concepts of social identity and shared understanding could be further developed in order to explain why the organizational context makes a difference in knowledge flows (Kogut and Zander, 1996; Kogut, 2000) as argued by KBV proponents. In this regard, a deeper understanding of the institutions where organizational knowledge is created, and of the social and cognitive mechanisms within which individuals work, is of crucial importance for the development of the knowledge-based view of the firm (Kogut, 2000).

Finally, drawing from evolutionary biology and more specifically from complexity theory, analysis of loosely-coupled systems as structural arrangements that enable the flexible flow of knowledge is an interesting area for further research (Anderson, 1999). 


\section{Conclusion}

Given the current theoretical perspectives on knowledge, KBV is not yet a theory of strategy (i.e., a theory that links independent variables to a specific conception of firm performance) that goes beyond the insights provided by the resource-based view and the related dynamic capabilities approach. That is, once knowledge is conceptualized as a resource, the thinking simply becomes a special case of the resourcebased view of the firm. Similarly, the empirical literature suggests that it is unlikely that we have a new theory of organization, given that internal and external knowledge transfer processes are not appreciably different.

So, what is the knowledge-based view? Our view is that KBV offers enormously useful theoretical insights, well grounded in empirical findings that address the multilevel social processes through which knowledge is sourced, transferred and integrated within and across organizations. Although KBV is not fully developed, there is already a surprisingly consistent body of empirical results that is capable of informing theory-building and managerial practice. These findings point to a knowledge-based theory that is consistent with a pluralistic understanding of knowledge, and a view of organizations as complex adaptive systems, where meaning is socially constructed through ongoing activities of semi-autonomous groups. The implications for strategy remain more distant.

\section{Bibliography}

Allen, T. J. (1977). Managing the Flow of Technology. Cambridge, MA, The MIT Press.

Almeida, P. (1996). “Knowledge Sourcing by Foreign Multinationals: Patent Citation Analysis in the U.S. Semiconductor Industry.” Strategic Management Journal 17(Winter Special Issue): 155-165.

Anderson, P. (1999). “Complexity Theory and Organization Science.” Organization Science 10(3): 216232. 
Argote, L. (1999). Organizational Learning: Creating, Retaining and Transferring Knowledge. Norwell, MA, Kluwer Academic Publishers.

Athanassiou, N. and D. Nigh (1999). “The Impact of U.S. Company Internationalization on Top Management Team Advice Networks: A Tacit Knowledge Perspective.” Strategic Management Journal 20: $83-92$.

Barney, J. (1991). "Firm Resources and Sustained Competitive Advantage." Journal of Management 17(1): 99-120.

Bechky, B. A. (1999). "Creating Shared Meaning across Occupational Communities: An Ethnographic Study of a Production Floor.” Working Paper.

Bierly, P. and A. Chakrabarti (1996). "Generic Knowledge Strategies in the U.S. Pharmaceutical Industry." Strategic Management Journal 17(Winter Special Issue): 123-135.

Blackler, F. (1993). "Knowledge and the Theory of Organizations: Organizations as Activity Systems and the Reframing of management.” Journal of Management Studies 30(6): 863-884.

Blackler, F. (1995). "Knowledge, Knowledge Work and Organizations: An Overview and Interpretation." Organization Studies 16(6): 1021-1046.

Brown, J. S. and P. Duguid (1991). "Organizational Learning and Communities of Practice: Toward a Unified View of Working, Learning and Innovation.” Organization Science 2(1): 40-57.

Brown, S. L. and K. Eisenhardt (1998). Competing on the Edge - Strategy as Structured Chaos. Boston, MA, Harvard Business School Press.

Brown, S. L. and K. M. Eisenhardt (1997). “The Art of Continuous Change: Linking Complexity Theory and Time-paced Evolution in Relentlessly Shifting Organizations.” Administrative Science Quarterly 42: $1-34$.

Capron, L. (1999). “The Long-Term Performance of Horizontal Acquisitions.” Strategic Management Journal 20: 987-1018. 
Chacar, A. and R. Coff (forthcoming). "Deconstructing a Knowledge-Based Advantage: Rent Generation, Rent Appropriation and Performance in Investment Banking.” Forthcoming in Bresser, R., Heuskel, D. and Nixon, R. Winning Strategies in a Deconstructing World. John Wiley \& Sons.

Cohen, M. D., R. Burkhart, et al. (1996). "Routines and Other Recurring Action Patterns of Organizations: Contemporary Research Issues.” Industrial and Corporate Change 5: 653-698.

Cohen, W. M. and D. A. Levinthal (1990). “Absorptive Capacity: A New Perspective on Learning and Innovation.” Administrative Science Quarterly 35(1): 128-152.

Conner, K. R. and C. K. Pralahad (1996). “A Resource-based Theory of the Firm: Knowledge vs. Opportunism.” Organization Science 7(5): 477-501.

Cook, S. D. N. and J. S. Brown (1999). "Bridging Epistemologies: The Generative Dance Between Organizational Knowledge and Organizational Knowing.” Organization Science 10(4): 381-400.

Cowan, R. and D. Foray (1997). “The Economics of Codification and the Diffusion of Knowledge.” Industrial and Corporate Change 6(3): 595-622.

Cyert, R. M. and J. G. March (1963). A Behavioral Theory of the Firm. Englewood Cliffs, NJ, PrenticeHall.

D'Aveni, R. A. (1994). Hypercompetition: Managing the Dynamics of Strategic Maneuvering. New York, The Free Press.

Decarolis, D. M. and D. L. Deeds (1999). “The Impact of Stocks and Flows of Organizational Knowledge on Firm Performance: An Empirical Investigation of the Biotechnology Industry.” Strategic Management Journal(20): 953-968.

Dierickx, I. and K. Cool (1989). “Asset Accumulation and Sustainability of Competitive Advantage.” Management Science 35: 554-571.

Dougherty, D. (1992). "Interpretive Barriers to Successful Product Innovation in Large Firms.” Organization Science 3(2): 179-202.

Dyer, J. H. (1999). "Interorganizational Learning, Barriers to Knowledge Transfers and Competitive Advantage.” Working Paper. 
Eisenhardt, K. (1989). “Making Fast Strategic Decisions in High-Velocity Environments.” Academy of Management Journal 32(3): 543-576.

Eisenhardt, K. M. and M. M. Bhatia (forthcoming) Organizational Complexity and Computation. In J.

Baum (ed.) Companion to Organizations, Blackwell Publishers.

Eisenhardt, K. M. and D. C. Galunic (2000). “Coevolving: At last, a Way to Make Synergies Work.” Harvard Business Review(January-February).

Eisenhardt, K. M. and J. A. Martin (1999). "Dynamic Capabilities: The Evolution of Resources in Dynamic Markets.” Strategic Management Journal- Forthcoming.

Foss, N. J. (1996). "Knowledge-based Approaches to the Theory of the Firm: Some Critical Comments." Organization Science 7(5): 470-476.

Galunic, D. C. and S. Rodan (1998). "Resources Recombinations in the Firm: Knowledge Structures and the Potential for Schumpeterian Innovation.” Strategic Management Journal 19: 1193-1201.

Graebner, M. (1999). A Review of Recent Research on Mergers and Acquisitions, Academy of Management 1999 - Chicago, IL.

Grant, R. M. (1996). “Toward a Knowledge-Based Theory of the Firm.” Strategic Management Journal 17(Winter Special Issue): 109-122.

Grant, R. M. (1996a). "Prospering in Dynamically-competitive Environments: Organizational Capability as Knowledge Integration.” Organization Science 7(4): 375-387.

Gupta, A. K. and V. Govindarajan (2000). "Knowledge Flow within Multinational Corporations.” Strategic Management Journal 21: 473-496.

Hansen, M. T. (1998). “Combining Network Centrality and Related Knowledge: Explaining Effective Knowledge Sharing in Multiunit Firms.” Harvard Business School - Working Paper.

Hansen, M. T. (1999). "The Search-Transfer Problem: The Role of Weak Ties in Sharing Knowledge Across Organizational Subunits.” Administrative Science Quarterly 44(1): 82-111.

Hargadon, A. (1998). Knowledge Brokers: A Field Study of Organizational Learning and Innovation. Academy of Management. 
Hargadon, A. and R. I. Sutton (1997). “Technology Brokering and Innovation in a Product Development Firm.” Administrative Science Quarterly 42: 716-749.

Helper, S., J. P. MacDuffie and C. Sabel (1999). "Pragmatic Collaborations: Advancing Knowledge while Controlling Opportunism.” Working Paper.

Henderson, R. (1994). "The Evolution of Integrative Capability: Innovation in Cardiovascular Drug Discovery." Industrial and Corporate Change 3(3): 607-629.

Henderson, R. and I. Cockburn (1994). "Measuring Competence? Exploring Firm Effects in Pharmaceutical Research.” Strategic Management Journal 15: 63-84.

Henderson, R. and I. Cockburn (1996). "Scale, Scope, and Spillovers: The Determinants of Research Productivity in Drug Discovery." RAND Journal of Economics 27(1): 32-59.

Inkpen, A. C. and A. Dinur (1998). "Knowledge Management Processes and International Joint-Ventures." Organization Science 9(4): 454-468.

Jett, Q. R. (1999). All the Right Moves: Linking Organizational Capabilities with Competitive Product Moves in Dynamic Markets. Working Paper.

Kale, P., J. H. Dyer and H. Singh (1999). Alliance Capability, Stock Market Response, and Long Term Alliance Success, Working Paper.

Katz, R. and M. L. Tushman (1981). "An Investigation into the Managerial Role and Career Paths of Gatekeepers and Project Supervisors in a Major R\&D Facility.” R\&D Management 11(103-110).

Kogut, B. and U. Zander (1992). "Knowledge of the Firm, Combinative Capabilities, and the Replication of Technology.” Organization Science 3(3): 383-397.

Kogut, B. and U. Zander (1996). "What Firms Do? Coordination, Identity, and Learning.” Organization Science 7(5): 502-523.

Kogut, B. (2000). “The Network as Knowledge: Generative Rules and the Emergence of Structure.” Strategic Management Journal 21: 405-425.

Lam, A. (1997). "Embedded Firms, Embedded Knowledge: Problems of Collaboration and Knowledge Transfer in Global Cooperative Ventures.” Organization Studies 18(6): 973-996. 
Lane, P. J. and M. Lubatkin (1998). "Relative Absorptive Capacity and Interorganizational Learning." Strategic Management Journal 19: 461-477.

Lave, J. and E. Wenger (1991). Situated Learning: Legitimate Peripheral Participation. Cambridge, UK, Cambridge University Press.

Leonard-Barton, D. (1992). "Core Capabilities and Core Rigidities: A Paradox in Managing New Product Development." Strategic Management Journal 13: 111-125.

Liebeskind, J. P., A. L. Oliver, L. Zucker and M. Brewer (1996). “Social Networks, Learning and Flexibility: Sourcing Scientific Knowledge in New Biotechnology Firms.” Organization Science 7(4): 428-443.

Lord, M. D. and A. L. Ranft (1998). "Transfer and Sharing of Local Knowledge within the Firm \& Entry into New International Markets.” Academy of Management Best Papers Proceedings '98.

Lorenzoni, G. and A. Lipparini (1999). "The Leveraging of Interfirm Relationships as a Distinctive Organizational Capability: A Longitudinal Study.” Strategic Management Journal 20: 317-338.

Martin, J. A. and P. R. Carlile (1999). Designing Agile Organizations: Organizational Learning at the Boundaries. Pressing Problems in Modern Organizations. R. E. Quinn, R. M. O'Neill and L. S. Clair. New York, Amacom.

McEvily, B. and A. Zaheer (1999). "Bridging Ties: A Source of Firm Heterogeneity in Competitive Capabilities.” Strategic Management Journal 20: 1133-1156.

Moreland, R. L., L. Argote and K. Ranjani (1996). Socially Shared Cognition at Work: Transactive Memory and Group Performance. What's Social about Social Cognition: 57-84.

Mowery, D. C., J. Oxley and B. Silverman (1996). "Strategic Alliances and Interfirm Knowledge Transfer." Strategic Management Journal17(Winter Special Issue): 77-91.

Mowery, D. C. and N. Rosenberg (1998). Paths of Innovation. Cambridge, MA, Cambridge University Press.

Nahapiet, J. and S. Goshal (1998). "Social Capital, Intellectual Capital and Organizational Advantage." Academy of Management Review 23(2): 242-266. 
Nelson, R. R. and S. G. Winter (1982). An Evolutionary Theory of Economic Change. Cambridge, Massachusets, Belknap - Harvard University Press.

Nonaka, I. (1994). "Dynamic Theory of Organizational Knowledge Creation." Organization Science 5(1): 14-37.

Nonaka, I. and H. Takeuchi (1995). The Knowledge-Creating Company. New York, Oxford University Press.

Okhuysen, G. A. and K. M. Eisenhardt (2000). “Integrating Knowledge in Groups: How Simple Formal Interventions Help.” Working Paper.

Orr, J. E. (1996). Talking about Machines: An Ethnography of a Modern Job. Ithaca, NY, Cornell University Press.

Patriotta, G. and A. Pettigrew (1999). “Studying Knowing and Organization.” Working Paper.

Penrose, E. (1959). The Theory of the Growth of the Firm. Oxford, Basil Blackwell.

Polanyi, M. (1962). Personal Knowledge - Towards a Post-Critical Philosophy. London, Routledge and Kegan Paul.

Porter, M. E. (1985). Competitive Advantage: Creating and Sustaining Superior Performance. New York, Free Press.

Porter, M. E. (1991). “Tow ards a Dynamic Theory of Strategy.” Strategic Management Journal12: 95-117.

Powell, W. W., K. W. Koput and L. Smith-Doerr (1996). "Interorganizational Collaboration and the Locus of Innovation: Networks of Learning in Biotechnology.” Administrative Science Quarterly 41: 116-145.

Pralahad, C. K. and G. Hamel (1990). "The Core Competence of the Organization.” Harvard Business Review(May-June): 79-90.

Ranft, A. L. and M. D. Lord (1998). “The Challenges of Acquiring Knowledge-Based Resources: Evidence from High-Tech Acquisitions.” Working Paper.

Ranft, A. L. and C. P. Zeithaml (1997). "Preserving and Transferring Knowledge-based Resources during Post-acquisition Implementation: A Study of High-Tech Acquisitions.” Working Paper. 
Roberts, P. W. (1999). "Product Innovation, Product-Market Competition and Persistent Profitability in the U.S. Pharmaceutical Industry.” Strategic Management Journal20: 655-670.

Rogers, E. (1980). Diffusion of Innovations. New York, Free Press.

Rosenkopf, L. and A. Nerkar (1999). "Beyond Local Search: Boundary-Spanning, Exploration and Impact in the Optical Disc Industry.” Working Paper.

Santos, F. M. (1999). "The Cognocratic Organization: Towards a Knowledge Theory View of the Firm." Presented at The Academy of Management 99 - Chicago, IL.

Shapiro, C. (1989). "The Theory of Business Strategy.” RAND Journal of Economics 20(1): 125-137.

Simon, H. (1965). Administrative Behavior. New York, Free Press.

Simonin, B. L. (1997). "The Importance of Collaborative Know-How: An Empirical Test of the Learning Organization.” Academy of Management Journal 40(5): 1150-1174.

Simonin, B. 1. (1999). “Ambiguity and the Process of Knowledge Transfer in Strategic Alliances.” Strategic Management Journal 20: 595-623.

Sparrow, J. (1998). Knowledge in Organizations. London, Sage Publications Inc.

Spender, J.-C. (1996). "Making Knowledge the Basis of a Dynamic Theory of the Firm.” Strategic Management Journal 17(Winter Special Issue): 45-62.

Stalk, G., P. Evans and L. E. Shulman (1992). "Competing on Capabilities: The New Rules of Corporate Strategy.” Harvard Business Review(March-April): 57-69.

Szulanski, G. (1996). "Exploring Internal Stickiness: Impediments to the Transfer of Best Practice Within the Firm.” Strategic Management Journal17(Winter Special Issue): 27-43.

Teece, D. J., G. Pisano and A. Shuen (1997). "Dynamic Capabilities and Strategic Management." Strategic Management Journal 18(7): 509-533.

Tell, F. (1997). Knowledge and Justification - Exploring the Knowledge Based Firm. Linkoping, Linkoping University.

Tripsas, M. (1997). “Surviving Radical Technological Change through Dynamic Capability: Evidence form the Typesetter Industry.” Industrial and Corporate Change 6. 
Tsoukas, H. (1996). “The Firm as a Distributed Knowledge System: A Constructionist Approach.” Strategic Management Journal 17(Winter Special Issue): 11-25.

Von_Krogh, G., J. Roos and D. Kleine, Eds. (1998). Knowing in Firms: Understanding, Managing and Measuring Knowledge. London, Sage.

Von_Krogh, G., J. Roos and K. Slocum (1994). “An Essay on Corporate Epistemology.” Strategic Management Journal 15: 53-71.

Weick, K. E. (1991). “The Nontraditional Quality of Organizational Theory.” Organization Science 2(1): $116-124$.

Weick, K. E. and K. H. Roberts (1993). "Collective Minds in Organizations: Heedful Interrelating on Flight Decks.” Administrative Science Quarterly 38: 357-381.

Wernerfelt, B. (1984). “A Resource-based View of the Firm.” Strategic Management Journal 5: 171-180.

Whitaker, R. (1996). “Managing Context in Enterprise Knowledge Process.” European Management Journal 14(4): 399-406.

Winter, S. (1987). Knowledge and Competence as Strategic Assets. The Competitive Challenge - Strategies for Industrial Innovation and Renewal D. Teece. Cambridge, MA, Ballinger.

Winter, S. G. and G. Szulanski (1999). "Replication as Strategy.” Working Paper - Presented at the 1999 Academy of Management Conference.

Zander, U. and B. Kogut (1995). "Knowledge and the Speed of the Transfer and Imitation of Organizational Capabilities: An Empirical Test.” Organizations Science 6(1): 76-92.

Zollo, M. and H. Singh (1999). "Post-Acquisition Strategies, Integration, Capability, and the Economic Performance of Corporate Acquisitions.” Working Paper - INSEAD 99/42/SM. 


\section{EndNotes}

\footnotetext{
${ }^{1}$ The authors gratefully acknowledge the helpful comments from Andrew Pettigrew, Gerardo Patriotta, Steffen Bohm, Jeff Martin and Mahesh Bhatia. The second author acknowledges the financial support from Program PRAXIS XXI (BD 16210/98).

${ }^{2}$ This discussion represents a simplification of a highly complex theme. For a deeper overview of individual knowledge, drawn mostly from cognitive psychology, see Sparrow (1998). For an in-depth discussion of organizational knowledge, see Tell (1997). For an interesting discussion on the contrast between Western and Eastern epistemology see Nonaka (1995).
} 